\title{
Corpo e saúde: uma controvertida produção coletiva
}

\section{Body and health: a controversial collective production}

\author{
1 Julio Cesar de Almeida Nobre julio.nobre@foa.org.br \\ 1 Ivanete da Rosa Silva de Oliveira \\ 2 Thabata Braga Mendes \\ 3 Angélica Silva Corrêa \\ 4 Vanessa de Fátima Leite

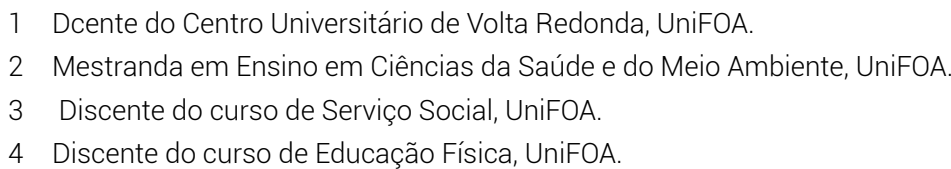

\section{Resumo}

Diversas são as tecnologias na atualidade a prometerem um corpo mais saudável, com contornos cada vez mais aperfeiçoados. Nesse sentido, vemos uma rede emaranhada de químicas, estatísticas, artigos acadêmicos, indústrias farmacêuticas, capital, universidades, academias, dentre outros mediadores, a coproduzirem aquilo que concebemos por saúde e corpo. Sendo assim, entendemos que a ironia é que, se por um lado, tais tecnologias prometem um corpo otimizado em suas capacidades entendidas como naturais, por outro, acabam no limite, por trazer vertigens para aquilo que, de fato, entendemos por corpo humano. Muitos são os autores que argumentam por um corpo que vem se expandido em suas potencialidades e adquirindo novas habilidades, na justa medida em que parece ser invadido por dispositivos diversos. Em tal terreno nos situamos: um corpo arredio e instável, um ideal de saúde imbricado com tecnologias, uma atualidade de intensa controvérsia sobre as possibilidades de caminhos a serem seguidos. São questões que se colocam na justa medida dos embates das diferentes mediações e tecem - conjuntamente - a realidade em que estamos imersos. Nesse sentido, a partir do referencial da Teoria Ator-rede, o presente trabalho objetiva desenvolver uma cartografia descritiva da produção daquilo que entendemos por saúde na atualidade, mediada pela busca de um corpo "perfeito" em sua interface com tecnologias atuais. A proposta é colocar em evidência a rede heterogênea de mediações que fazem circular formatos acerca da saúde do corpo, bem como as diversas resistências em tal circulação.

\section{Palavras-chave}

Teoria Ator-rede; corpo; saúde; tecnologia.

\begin{abstract}
Several technologies are today pledged to a healthier body, with increasingly sophisticated contours. In this sense, we see a tangled web of chemicals, statistics, academic articles, pharmaceutical industries, capital, universities, academies, among other mediators to co-produce what we conceive as health and body. Thus, we understand that the irony is that, if on the one hand, these technologies promise an optimized body in their capabilities understood as natural, on the other hand they, they end up in the limits, in fact, understand the body human. Many are the authors who argue for a body that has been expanded in its capabilities and, acquiring new skills just as it appears to be invaded by various devices. In such a ground we stand: an elusive and unstable body, an ideal of health interwoven with technology, a present of. Intense controversy about the possibilities of paths to follow. These are questions that arise in the full measure of the clashes of different mediations, and weave together - the reality in which we are immersed. In this sense, from the reference actor-network theory, this paper aims to develop a descriptive mapping of the production of what we mean by health today, mediated by the search for a "perfect" body in its interface with current technologies. The idea is to highlight the heterogeneous network of mediation that make circular shapes on the body's health, and the various resistances in such circulation.
\end{abstract}

\section{Keywords}

Actor-network theory; body; health; technology.

\section{Como você deve citar?}

NOBRE, Julio Cesar de Almeida et al.. Corpo e saúde: uma controvertida produção coletiva. Cadernos UniFOA, Volta Redonda, n. 31, p. 59-73, ago. 2016. 


\section{INTRODUÇÃO}

Discutir o conceito de saúde implica compreender a produção do modo como o homem vem lidando com a questão da finitude da vida. Nessa perspectiva, o corpo saudável parece torna-se um status a ser conquistado. Entretanto, as concepções de saúde parecem extrapolar os limites de um corpo simplesmente harmônico, adaptado e em conformidade com padrões estéticos cristalizados. Tais concepções estão fundamentadas em práticas de intervenção que, entre outras coisas, visam aprimorar os requisitos articulados a índices de mortalidade que vêm sendo ampliados.

Nesse cenário, a ação da tecnologia assume uma posição significativa nos processos produtivos que estão atrelados às concepções de corpo e, por consequência, de saúde e contribuindo para uma atualidade na qual múltiplos atores fazem circular diferentes abordagens. Dentre essas abordagens, muitas delas estão articuladas a aspectos biológicos, fisiológicos e mecânicos, como demonstradas nas obras de Boorse (1975, 1977 apud FARINATTI; FERREIRA, 2006), expoente da concepção biomédica de causa e efeito que contrapõe saúde à doença.

Para ele [Boorse], no corpo humano saudável (tanto física quanto mentalmente), cada órgão ou sistema deve executar sua função a contento, contribuindo com os propósitos essenciais da sobrevivência e da reprodução. Os estados particulares que levam a uma inibição dessas funções passam a constituir, por extensão, as doenças. (FARINATTI; FERREIRA, 2006, p. 35)

Essa concepção de saúde centrada no indivíduo que enfatiza os fatores causais e a necessidade do controle da saúde por vias externa articula-se aos ideais sanitaristas e normas biológicas de um funcionamento orgânico. Outras, por sua vez, trazem atributos que realçam aspectos associados à capacidade de assegurar a autoestima mediante práticas de autocuidado. Encontramos aqui uma forte articulação com a concepção do ser integral. Esse outro modo de conceber saúde, difundido principalmente pela Organização Mundial de Saúde (OMS) que, desde 1948, passou a definir saúde como "estado completo de bem-estar físico, mental e social, e não apenas a ausência de doença" (SERGE; FERRAZ, 1997, p. 539), nos possibilita afirmar que

\footnotetext{
os dados provenientes das ciências biológicas e médicas, [...] passaram a ser interpretados como informações que vinham reforçar a importância dos parâmetros sociológicos e ecológicos da saúde. Dessa forma, um novo desacordo se produz entre uma visão reducionista [...] e uma abordagem mais holística da condição humana. Torna-se cada vez mais claro que os perfis de saúde e de enfermidade dependem das condições mais gerais de vida (FARINATTI; FERREIRA, 2006, p. 38-39).
}

Nessa perspectiva, as condições socioeconômicas e políticas, associadas às condições ocupacionais e de subsistência, tornavam-se aportes para induzir novos modos de vida compatíveis com o que se compreende por saúde. Apesar da ampliação do entendimento da temática, isso ainda não se mostrava suficiente para conceituar o que seria saúde ou até mesmo o corpo saudável.

Tais concepções, bem como a própria saúde, parecem convergir para uma mesma finalidade: a manutenção e o prolongamento da vida. Todavia, a atualidade insinua uma diluição desse entendimento, deslocando o pensar saúde, potencializado pela tecnologia, para a obtenção de um corpo "perfeito". Assim, tal corpo parece se produzir imbricado a actantes diversos, cujas ações não respeitam fronteiras traçadas, sejam elas de qualquer ordem. Uma saúde corporal parece se produzir como um efeito de redes de mediadores em ação a misturar esteroides, com cirurgias plásticas, químicas, estatísticas, conselhos profissionais, políticas públicas, grande mídia, produção e circulação de artigos acadêmicos, capital, indústrias farmacêuticas, academias, etc.

Diversas são as tecnologias na atualidade que parecem prometer um corpo com contornos cada vez mais aperfeiçoados. Nesse sentido, vemos uma rede emaranhada de mediadores a coproduzirem aquilo 
que concebemos por corpo e saúde. Uma perfeição articulada com práticas dotadas da capacidade de purificar tal corpo, livrando-os das imperfeições dos "erros de percurso". A ironia é que, se por um lado, tais tecnologias prometem um corpo otimizado em suas capacidades, entendidas como naturais, por outro, acabam, no limite, por trazer vertigens para aquilo que, de fato, entendemos por corpo humano. Um corpo que vem sendo expandido em suas potencialidades: "(...) percebemos que o corpo está ampliando as suas antigas habilidades, capacidades e adquirindo novas. $O$ novo corpo cognitivo tem percepções, memórias e espaços estendidos" (LESSA, 2003, p. 1). E invadido por dispositivos: "(...) invadem este corpo através de vários dispositivos como: tomografia computadorizada, angiografia, laparoscopia, ecografia, ressonância magnética, corações artificiais, braços mecânicos entre outros" (LESSA, 2003, p. 1- 2).

Em tal terreno nos situamos: um corpo arredio e instável, um ideal de saúde imbricado com tecnologias em uma atualidade de intensa controvérsia sobre os caminhos a serem seguidos. Assim, o presente artigo tem por objetivo o desenvolvimento de uma breve cartografia descritiva dos processos de produção daquilo que se entende por saúde do corpo na atualidade.

\section{A SAÚDE DO CORPO}

O conceito de saúde, articulado às questões valorativas que indicam qual é o estado saudável do ser humano, parece passar por constantes modificações, na atualidade. Quando nos debruçamos sobre alguns fatores articulados a tais transformações, podemos destacar o processo de industrialização que vem acarretando mudanças sociais e, consequentemente, afetando radicalmente as concepções acerca da saúde e da doença. Outro fator, a urbanização, que está intrinsecamente articulada aos avanços do processo industrial, também trouxe impactos consideráveis para o indivíduo, criando ambientes e situações antes inusitadas no cotidiano.

A partir da metade do século XVIII, importantes transformações passaram a ocorrer na Europa, com impactos notáveis sobre as condições de vida e saúde. A urbanização acelerada e a industrialização são com frequência os processos mais destacados, tanto por seus impactos sobre as condições de produtividade como nas condições de trabalho e qualidade de vida da classe trabalhadora (SABROZA, 2001 p. 1).

Um dos principais enfoques atrelado ao conceito de saúde, quase sempre, se relaciona a doenças do indivíduo e a sua condição produtiva em relação à sociedade que o cerca. Desse modo, a concepção que perdurou durante séculos e que ainda resvala na atualidade, gira em torno da busca incessante do homem saudável através das questões da saúde como mera ausência de doença.

A partir do Renascimento, a hegemonia do clero é abalada [...] o que possibilita, por exemplo, a prática da dissecação
de cadáveres e o reconhecimento da função de fato, de estruturas biológicas as quais antes não se tinha ideia. [...]
Dessa forma, o paradigma simbólico, sustentado em crenças e representações religiosas, passa gradativamente a
ser substituído pelo empirista e positivista [...]. Alguns autores definem que a expressão maior do novo modelo de
concepção de homem, aplicado à saúde e iniciado com o Renascimento, terá seu apogeu com o estabelecimento
do entendimento biomédico. Esse conceito tem em sua base a ideia de que o ser humano é um sistema biológico,
onde outros pontos de vista sobre o mesmo, como o psíquico e social, não precisam ser considerados para o juízo
do processo de adoecimento. Nessa perspectiva, a ênfase do tratamento recai majoritariamente sobre o profissional
da saúde, pois este sim é estimado como o portador do saber biológico, deixando o paciente destituído de ação, em
função do seu desconhecimento específico sobre as leis que regem seu próprio organismo. (SBISSA et al., 2011, p. 95)

Em contraposição, esse modelo biomédico foi sendo instabilizado a partir de outros aspectos de valoração que passam a influenciar a produção do homem saudável, como a estética, a moral, a cultura e, até mesmo, a política. 


\begin{abstract}
Essa exacerbação do referencial naturalista teve como principal consequência um movimento contrário que revogou, para o raciocínio terapêutico, a inclusão de outras formas de pensar, como o psicológico e social. Dessa maneira, o indivíduo passa também a ser responsável pelo seu próprio bem estar, pois agora, não somente células, hormônios, neurotransmissores são levados em consideração, como fatores determinantes, mas também, estilo de vida, relacionamento social, contexto ambiental, valores e crenças. Assim sendo, inúmeras práticas, agora conhecidas como complementares passaram a fazer parte do repertório de técnicas utilizadas pelos sistemas de saúde dos principais países ocidentais desenvolvidos, como os EUA, Alemanha, Inglaterra, Austrália, etc. (SBISSA et al., 2011, p. 95)
\end{abstract}

A ascensão do conceito de saúde tratado pela Organização Mundial de Saúde (OMS), importante porta-voz nessa temática, que o define não apenas como a ausência de doença, mas como a situação de perfeito bem-estar físico, mental e social, está embebido no movimento contrário ao conceito linear de saúde positivista. Desse modo, levanta controvérsias e objeções acerca do significado do conceito de perfeição no bem-estar - visto que nem sempre é possível caracterizar o que é perfeito, pois o termo e a própria condição são dotados de profundas diferenças. Entende-se que, ao definir algo como perfeito, é preciso considerar um conjunto de relações tais como: quem o avalia, quem está sendo avaliado, quais são os parâmetros de avaliação e para qual referencial de saúde eles tendem.

\begin{abstract}
A saúde não é um "estado estável", que uma vez atingido possa ser mantido. A própria compreensão de saúde tem também alto grau de subjetividade e determinação histórica, na medida em que indivíduos e sociedades consideram ter mais ou menos saúde dependendo do momento, do referencial e dos valores que atribuam a uma situação. [...] Diversas tentativas vêm sendo feitas a fim de se construir um conceito mais dinâmico, que dê conta de tratar a saúde não como imagem complementar da doença e sim como construção permanente de cada indivíduo e da coletividade, que se expressa na luta pela ampliação do uso das potencialidades de cada pessoa e da sociedade, refletindo sua capacidade de defender a vida. (BRASIL, 1997, p.65)
\end{abstract}

A partir dessas informações, a saúde começa a se desarticular do conceito de doença, englobando outras dimensões e se complexificando, podendo sofrer ações de várias frentes, de várias ordens. Por isso, muitos são aqueles que, na atualidade, apontam a importância de se expandir a maneira de abordar tal conceito, de forma permanente. Saúde como "o não estar doente", parece se produzir como definição limitada, visto que nem sempre a ausência de sinais e sintomas indica a condição saudável e, mais ainda, muitos se consideram saudáveis, ainda que portadores de uma enfermidade.

Atualmente, em debate, diversos autores têm criticado essa definição negativa de saúde, tais como Almeida Filho e Andrade ao defenderem que

(...) em uma perspectiva rigorosamente clínica (...) a saúde não é o oposto lógico da doença e, por isso, não poderá de modo algum ser definida como 'ausência de doença'. (...) os estados individuais de saúde não são excludentes a ocorrência de doença. (ALMEIDA FILHO; ANDRADE, 2003, p. 101).

Esses autores, ao apreender o homem como um ser sociopolítico e cultural, não negligenciam a diversidade de fatores que impactam as relações entre o binômio saúde/doença. Com a entrada de tal complexidade na abordagem da saúde, passa-se a produzir uma crítica, na atualidade, que denuncia uma saúde cada vez mais desarticulada da condição de direito social, passando a se produzir como um bem de serviço. Assim, "[...] a destruição do meio ambiente, a miséria social, a formação de cartéis na indústria farmacêutica, os altos custos do tratamento médico e o distanciamento cada vez maior na relação médicopaciente" (SBISSA et al., 2011, p. 99), acabam por se imbricar fortemente com a fabricação desse cenário.

Nesse contexto, as concepções de saúde e, concomitantemente, do corpo saudável, vão se alterando e sendo influenciadas por interesses diversos que estão articulados aos cuidados com a pessoa - inclusive, fomentando práticas complementares à ação médica, tais como o exercício físico, as terapias alternativas, etc. Diante das diversas práticas atuais que buscam articular corpo com saúde, o corpo humano vem desempenhando novas e diferenciadas funções. Esses desempenhos acabam por não se restringirem a uma dimensão imbricada tão somente à perspectiva de um corpo saudável. Apresenta aspectos característicos de um corpo torneado com definições musculares acentuadas conhecidos como perfil body fitness. Hoje o corpo é comercializado como um meio de obtenção de status e vinculado às diversas relações de poder. 
Com o desenvolvimento da tecnologia no âmbito da tecnociência, a transformação do corpo se torna possível diante do anseio de ampliação da capacidade física que está articulada a uma condição biológica, da qual o humano parece lutar para tornar obsoleta. Toda essa busca pelo corpo perfeito parece se articular com desejos, prazeres, saberes e poderes do indivíduo, de modo a obter seus contornos sociais. Tais contornos passam a figurar como conquistas da realização de seus objetivos e respostas a suas necessidades.

Para melhor abordar tal cenário, no qual o corpo parece começar a ser concebido como algo "perecível", o conceito de homem pós-orgânico, de Paula Sibilia (2002), pode ser um importante operador. Tal autora parte, em seu argumento, do pressuposto da existência de duas vertentes filosóficas na cultura ocidental: a prometeica e a fáustica. A tradição prometeica nos remete ao domínio do divino, no sentido de que não seria da competência do homem profanar o que é sagrado - enquadrando aqui os limites impostos pela natureza humana. 0 foco, aqui, seria uma ação que objetive o bem humano. Teríamos uma tecnociência apenas instrumental, voltada para a melhoria desse humano. Tal tecnociência teria limites, visto que a própria racionalidade os teria. 0 misterioso e imponderável restringiria as possibilidades do alcance humano.

Por outro lado, a tradição fáustica, questionadora da tradição prometeica, visa à ampliação dos limites da vida e da morte diante da transformação e ultrapassagem da própria condição humana e de seu corpo natural. Teríamos, aqui, uma Ciência intimamente articulada à tecnologia, que não se contentaria em explicar os fenômenos naturais e as verdades do mundo, mas sim a previsão e controle da realidade (SIBILIA, 2001). A partir de tais considerações, ao voltarmos nosso olhar para uma atualidade de constante reconfiguração do ser humano, podemos afırmar que a perspectiva fáustica articulada à tecnociência parece estar na ordem do dia. Através dos avanços da biotecnologia, cada vez mais se pode decidir quando morrer, o envelhecer ou não envelhecer, dentre outros. 0 corpo, sob a luz da teoria fáustica, passa a ser invadido por dispositivos diversos. Possibilidades tecnológicas avançam por sobre suas fronteiras consideradas naturais: corações artificiais, braços mecânicos, ressonância magnética, tomografia computadorizada, pinos de titânio, angiografia, etc.

A atualidade permite que uma discussão sobre os limites entre o natural e não natural venha à tona, trazendo fortes controvérsias para fronteiras que, até então, pareciam tácitas. A exploração do corpo está além da questão que permeia a sua infinitude. Essa discussão se desenvolve com base nas intensas inovações tecnológicas, nas práticas utilizadas pela ciência que acabam por possibilitar a circulação de novas possibilidades corporais, suas disseminações e compartilhamentos em um fluxo social. A produção de um corpo "livre", que venha a ser manuseado e comercializado parece despontar. Garcia dos Santos (2003) aponta para a constituição de um corpo operacional e não mais apenas representacional. Fronteiras flexíveis, um corpo agora entendido como recurso, matéria-prima para inovações.

Assim, na conquista fáustica de espaço por parte dos humanos, por sua transcendência (SIBILIA, 2002), um corpo flexível acaba por se articular com diversos atores, humanos e não humanos. Interesses e influências diversas coparticipam dessa produção. Na busca pela adequação e melhoria constante do corpo, temos tais fronteiras imbricadas ao mercado industrial, por exemplo, com seus produtos destinados ao aperfeiçoamento da forma física.

Estamos diante, portanto, de uma profunda controvérsia a envolver um processo de transformação do corpo. Diversas são as argumentações acerca das consequências de uma suposta potencialização do humano e seu corpo, para além de suas limitações orgânicas/naturais atuais. A maneira como condicionamos o corpo traz significativas vertigens em suas fronteiras, misturando-o com recursos tecnológicos. Híbridos de humano e não humano (células, músculos, genes, próteses, drogas, máquinas, etc) parecem transcender barreiras diversas, desvinculando o ser humano de fundamentos rígidos. Alguns argumentos parecem transitar por um entusiasmo diante das possibilidades de um corpo livre para ser explorado. 
Políticas de marketing propagam imagens e veiculam um ideário corporal perfeito e saudável, envolto por todo um apelo do modo estético. Tais posicionamentos parecem remeter à tradição fáustica, em uma busca que não se limita apenas à manutenção da capacidade física, da saúde do organismo humano, mas enfoca a superação da condição atual. 0 corpo, antes visto como o guardião sagrado da alma, passa a se produzir como base para a criação de uma nova condição. Porém, questionamentos diversos, críticas despontam na direção de uma suposta fragmentação e extinção do corpo enquanto humano. Muitos são os argumentos que traduzem nossa atualidade como articulada a uma possível prática de higienização - não racial, como aquelas levadas a cabo pelos nazistas em seu ideário de extermínio dos judeus, mas sim da condição humana de toda raça. 0 entendimento de um corpo higienizado deriva de um corpo desprovido de doenças, anomalias e mazelas celulares provenientes de sua forma natural. Uma busca por um patamar evolutivo superior que está articulado à promessa de um corpo sempre saudável e perfeito, mantido à base de medicamentos da indústria farmacêutica, intervenções cirúrgicas ou artefatos tecnológicos que acabam por trazer significativas vertigens - e consequente controvérsia - às fronteiras entre o humano e não humano. Segundo Garcia dos Santos (2003), o humano estaria sendo atingido em dois níveis: o da espécie, pois as manipulações genéticas poderiam causar o retorno da eugenia; e do indivíduo que, considerado predisposto às doenças e a certos comportamentos, poderia ter suas liberdades individuais desrespeitadas na busca por um padrão saudável.

É nesse cenário que desponta a temática do presente artigo. Articulado à tecnologia que parece desconstruir o humano, que corpo estaria despontando em meio a um processo de circulação imbricado a uma multiplicidade de atores humanos e não humanos? Entendemos que o referencial da Teoria Atorrede - TAR - se revela como bastante fértil na abordagem de coletivos complexos e, nesse sentido, acaba por ser um importante aliado em nossa proposta.

\section{A TEORIA ATOR-REDE}

A Teoria Ator Rede (TAR), referencial teórico-metodológico que tem como expoente o sociólogo das ciências Bruno Latour, possibilita uma análise do modo como toda e qualquer realidade é constantemente redefinida. Assim, em um constante desdobramento social, os fatos vão se constituindo de mediador em mediador, em meio a deslocamentos diversos. 0 mediador, entendido como humanos e não humanos que possuem a capacidade do desvio, seria um conceito-chave para o entendimento do modo como a realidade é articulada e propagada (LATOUR, 2000).

$\mathrm{Na}$ TAR, um ator é sempre definido a partir do papel que desempenha, do quanto é atuante e repercussivo. 0 foco aqui é o seu impacto, o efeito que causará na rede. Por sua vez, entendemos rede como todas as interligações e conexões, os nós agenciados pelos atores. Assim, uma rede sempre dependerá daquilo que os atores/mediadores farão com ela, podendo ser produzida para qualquer direção.

Tendo por referência o trabalho de mediadores diversos, uma análise de redes acaba por se revelar como uma cartografia, um método de estudo que rastreia a presença e ação de múltiplos atores, observando as articulações realizadas por eles, pertinentes à temática proposta. Assim, busca-se produzir um relato - bastante rico, porque repleto de mediadores - que traduza a produção de uma realidade tecidas de elo em elo, em redes de articulações. Tais amarrações são sempre necessárias, para que uma respectiva fronteira seja construída e perpetuada. Desse modo, um fato pode-se produzir na condição de rígido e indiscutível.

Ao voltarmos nosso olhar para a produção dos fatos, chamamos atenção para os conceitos de caixa-cinza e caixa-preta. 0 conceito de caixa-preta articula-se com a concepção de que todo e qualquer fato ganha solidez sempre que é inserido em novas formulações na condição de uma ideia indiscutível, 
como premissa. A caixa-preta caracteriza-se pela ausência de maiores controversas, por uma circulação mais estável, na qual o trabalho dos mediadores fica mais escondido. A caixa-cinza, por sua vez, consiste em uma circulação que revela a cozinha dos fatos, a instabilidade de uma realidade ainda em formação. Temos aqui um intenso processo de controvérsia. Enquanto o regime de caixa-preta caracteriza-se pela ausência de discussões e conflitos, o regime de caixa-cinza é permeado pelos questionamentos diversos e formação de polos dispostos em oposição - grupos e antigrupos (LATOUR, 2008).

Uma batalha de argumentos e contra-argumentos desponta em controvérsia, instabilizando um regime estável até então. Tal batalha não respeita fronteiras estabelecidas a priori. Temos ciência, direito, papéis, cidadãos comuns, materiais, dinheiro, religião, dentre outros, trazidos como aliados daqueles que pretendem produzir um fato sólido. Quando um argumento começa a se formar e servir como base para renovadas formulações, um novo fato parece se produzir, na medida em que tal instabilidade coletiva parece ceder espaço. Assim, sempre que uma realidade for tratada por natural, como um fato indiscutível, é possível rastrear o modo como ela se produz, circula. De mediador em mediador, elo em elo, acompanha-se cadeias de transformação.

Ao voltarmos nosso olhar para a temática do respectivo artigo, podemos observar que a busca por um corpo perfeito e saudável acaba por gerar uma forte controvérsia a envolver as próprias fronteiras do corpo humano e daquilo que entendemos por corpo e saúde. Em meio a intensas controvérsias, encontramos diversos argumentos produzidos e disseminados, mediadores e traduções que fazem o corpo e a saúde circularem por renovados circuitos. Em meio a tais produções é que nos situamos. Controvérsias que amarram em um mesmo destino, profissionais da saúde, academias de ginástica, biotecnologias, grandes empresas, a grande mídia, dentre outros.

Desse modo, a controvertida produção do corpo prefeito parece se pautar por questões acerca da saúde e do uso da tecnologia, no sentido de condicionar e controlar esse corpo humano - ou não humano. A intencionalidade no uso da TAR nesse universo de saúde seria de realizar um relato acerca das mediações que produzem a saúde do corpo humano na atualidade. 0 objetivo não é de aprofundarmos em um estudo que venha a criticar algo existente. Nosso foco será a análise das controvérsias que produzem uma realidade, a saúde do corpo em ação, rastreando e cartografando o trabalho dos mediadores entrelaçados, que produzem fronteiras na justa medida de seus trabalhos. Como porta de entrada para o respectivo instável coletivo, escolhemos a mídia especializada, bem como a grande mídia, na medida em que ambas reverberam, de modo bastante intenso, os diversos argumentos sobre a presente temática.

\section{CARTOGRAFANDO CONTROVÉRSIAS ACERCA DA SAÚDE DO CORPO}

Ao nos aproximarmos da respectiva controvérsia acerca da saúde do corpo a circular pela mídia, encontramos um artigo intitulado "A ditadura da estética: a busca pelo corpo perfeito", publicada em 11 de novembro 2009, na Revista Portal Puc-Rio Digital, na qual a produção do corpo perfeito é traduzida como um padrão estético a escravizar os indivíduos, principalmente em relação às mulheres. Nesse argumento, os exercícios físicos e o uso de cosméticos são trazidos como alternativas na busca por um corpo purificado, sem imperfeições.

O sedutor mercado da beleza atrai, a cada dia, mais pessoas com a promessa de soluções para todo e qualquer deslize da natureza ou castigo do tempo. Além da própria satisfação, elas procuram admiração que, quando acaba, provoca uma nova procura pela reparação de suas características físicas. O processo torna-se um ciclo, uma luta incessante por padrões pré-estabelecidos (ROSA, 2009).

Podemos observar, aqui, que a necessidade de estar belo parece extrapolar as possibilidades do corpo entendido como natural, sendo constantemente modificado e transformado. Cirurgias estéticas seriam 
recursos a serem utilizados. Temos um mercado da beleza traduzido como uma promessa de correção de um corpo articulado a defeitos. 0 artigo, porém, se coloca como um contraponto a tal cenário por ele construído. A busca por um corpo belo é traduzida como um adversário do corpo saudável. 0 caminho no sentido de um corpo magro e desejável teria seus efeitos colaterais. Casos de bulimia e anorexia, transtornos alimentares, seriam consequências oriundas dessa obsessão por um corpo esbelto e esguio. "A anorexia e a bulimia também fazem parte da lista das doenças que sofrem influência da 'beleza imposta'(...), o desejo de emagrecer e uma visão distorcida do corpo são características comuns" (ROSA, 2009).

0 artigo traz como aliado do seu argumento a psicóloga Joana Vilhena, que aponta que nossa atual sociedade focalizada no espetáculo, na imagem, tem horror à gordura. Assim, a imagem da magreza estaria associada a um cuidado com o corpo, trazendo uma consequente avaliação moral, na qual pessoas seriam selecionadas com referência à aparência. Teríamos, portanto, uma correlação entre caráter e imagem e, mais ainda, associa tal correlação à velocidade, ao imediato. No dizeres da psicóloga,

antigamente, para ser reconhecido, admirado, você tinha que percorrer um longo caminho. Hoje, você tem como contraponto ao sacrifício a ideia do imediatismo. Então, a pessoa quer emagrecer e ser reconhecida logo, sem pagar o preço desse sacrifício (ROSA, 2009).

Podemos observar forte sintonia entre a presente matéria e os argumentos encontrados no artigo "Em busca do corpo perfeito", publicado na Revista Veja Rio, em 15 de janeiro de 2014. Temos aqui, um argumento acerca da presença de forte tendência comportamental, no sentido da busca por uma diminuição do índice de gordura corporal. Porém, diferentemente do artigo anterior, parece mais ufanista na defesa por tal busca - parecendo vincular mais o seu texto com uma proposta de saúde do corpo. Seu argumento passa por uma combinação de exercícios físicos, dietas e um novo aliado: os testes genéticos, visto que a definição de uma dieta correta e adequada seria muito mais precisa, a partir do levantamento das características genéticas do indivíduo.

Com 32 anos, 54 quilos e 1,64 metros, a atriz Juliana Knust se enquadra na categoria à qual boa parte das muIheres almeja chegar: a das que têm um corpo sem nenhum sinal de gordura. Para manter a forma, ela adota a fórmula da dieta restritiva conjugada a exercícios, com foco na corrida. Há dois meses, partiu para um caminho alternativo. Resolveu esmiuçar seus genes para descobrir como pode usar a herança genética em benefício das curvas perfeitas. (BOTELHO, 2014)

Nesse sentido, a matéria traz alguns aliados que convergem em defesa do argumento de eficácia. Um laboratório em San Diego, nos Estados Unidos, por exemplo, fez vários testes genéticos científico-experimentais em uma atriz conhecida, Juliana Knust - que se prestou como sujeito de pesquisa. Temos aqui, mais uma alternativa de alta tecnologia como aliada na busca por um corpo perfeito, a genética, articulada à imagem de uma celebridade que parece fortalecer a informação posta em circulação, conjuntamente com a utilização do laboratório americano.

Para isso, coletou uma amostra de saliva, que foi acondicionada em um tubo e enviada a um laboratório em San Diego, nos Estados Unidos. (...) Ao adotar um novo estilo de vida a partir dessa análise, pude perceber que os benefícios são reais", conta ela, que é mãe de um menino de 3 anos e hoje exibe 2 quilos a mais de músculos e $3 \%$ a menos de gordura (BOTELHO, 2014).

Porém, a matéria traz uma controvérsia importante: segundo médicos e especialistas, existe dúvida em relação à eficácia dessa abordagem para efeitos de emagrecimento. 0 texto afirma que cientistas recomendam cautela quanto a uma possível banalização desse recurso, quando vinculado a um conceito saúde. 
Do ponto de vista da medicina, os testes genéticos constituem uma novidade que precisa ser encarada com cautela. Apesar de os cientistas já conhecerem muitos dos genes e mutações envolvidos nos processos que levam a doenças ou disfunções, pouco se sabe em que momento e como ocorre o gatilho para que esses males se desenvolvam. Com isso, muitas das informações de que hoje dispomos são meramente especulativas (BOTELHO, 2014).

Em artigo intitulado "O corpo perfeito saudável e sem anabolizantes", publicado na Revista Corpore, em 29 de outubro de 2014, encontramos um argumento que faz a saúde do corpo circular por uma oposição ao uso de anabolizantes.

Atualmente, homens e mulheres buscam formas esteticamente mais definidas e vultuosas, que simbolizem força e poder. Entretanto, essa busca pode levar ao uso indiscriminado de anabolizantes esteroides, substâncias sintéticas similares aos hormônios masculinos (testosterona) e de crescimento (GH), que em aumento da massa muscular e diminuem a massa gordurosa corporal (CORPORE, 2011).

A matéria acaba por articular corpo saudável com acompanhamento médico, treinos e alimentação balanceada, fazendo circular um discurso, no qual todas essas práticas são traduzidas como não agressoras do corpo. $\mathrm{O}$ argumento mantém imbricados a academia de musculação, o treinador e o ambiente virtual com uma promessa de fazer um corpo forte e saudável, com resultados eficazes e imediatos com o uso dos anabolizantes. Tais produtos entrariam como um recurso estético, nessa busca pelo corpo perfeito.

O estudante Felipe, de 20 anos, começou a usar anabolizantes injetáveis estimulados pelo personal trainer. "Pesquisei muito na internet sobre treinamentos e dietas alimentares para ganhar músculos e comecei a usar anabolizantes quando passei a treinar na academia", revela. De acordo com a $\mathrm{Dr}^{\mathrm{a}}$ Rafaela, o paciente foi levado pelos pais para fazer uma consulta porque estava apresentando um comportamento exagerado em relação à atividade física e à alimentação (CORPORE, 2011).

Esse argumento acaba por articular a busca pelo corpo perfeito aos malefícios do uso de esteroides. Saúde do corpo e busca pelo corpo perfeito se produzem como opostos em tal circulação. Tal mediação parece se fortalecer com a presença de uma profissional da saúde que defende a não utilização do anabolizante.

Apesar da proibição, é comum o consumo de anabolizantes prescritos por profissionais sem competência ou permissão legal para tal, na maioria das vezes em condições adversas e em altas doses, causando danos irreversíveis à saúde, alerta a $\mathrm{Dr}^{\mathrm{a}}$. Rafaela Perraro Sanderson, especialista em Endocrinologia e Metabologia que atua na Clínica Contato, em Curitiba (CORPORE, 2011).

\section{A endocrinologista continua:}

O uso de suplementos alimentares sem avaliação médica, com intuito de aumentar a massa magra, pode causar sobrecarga renal, assim como o uso de substâncias termogênicas indiscriminadamente, para aumentar o metabolismo, pode causar problemas cardíacos, acentua a endocrinologista. Por isso, é fundamental que estes suplementos também sejam prescritos por um especialista em Endocrinologia e Metabologia, juntamente com uma avaliação nutricional detalhada, para a indicação correta de suplementação, de acordo com a necessidade de cada organismo (CORPORE, 2011).

A saúde do corpo, aqui, se articula com a própria Endocrinologia, Metabologia e com avaliação nutricional, ou seja, a saúde está conectada ao conhecimento científico.

Em dois artigos do site UOL, encontramos argumentos acerca do quadro de saúde da modelo Andressa Urach. 0 primeiro, intitulado "Andressa Urach já respira sem a ajuda de aparelhos, diz boletim médico" (2014), relata as condições de saúde em que a ex-miss bumbum foi internada, respirando com a ajuda de aparelhos. Apresentava o diagnóstico de infeç̧ão por conta de uma aplicação de hidrogel nas pernas realizada no passado. Já o segundo, intitulado, "Globo destaca estado de saúde de Andressa Urach em telejornal" (2014), está relacionado à veiculação da notícia por uma grande emissora que deu destaque ao ocorrido com a modelo. 
A modelo está hospitalizada na unidade de saúde desde o dia 29 de novembro, quando chegou acompanhada pela mãe. Na ocasião, Andressa apresentava um processo infeccioso decorrente da aplicação de hidrogel nas pernas, realizado há cinco anos em uma clínica especializada. 0 estado de saúde da apresentadora é considerado grave (UOL TV E FAMOSOS, 2014).

A matéria argumenta por uma articulação da produção tecnológica do corpo com a necessidade em se tornar uma celebridade. Imbrica a saúde do corpo com status, fama, dinheiro e luxo. Urach se utilizou de métodos ofertados pela indústria estética e cirúrgica, por profissionais de saúde, como os cirurgiões. Temos aqui um circuito a entrelaçar intervenções cirúrgicas realizadas em clínicas clandestinas ou especializadas, dinheiro, prótese de silicone nas mamas, no bumbum, na panturrilha, lipoaspiração, plástica no nariz, botox nos lábios na face, hidrogel, enfım, um verdadeiro arsenal em prol da beleza estética como conceito de boa forma e saúde.

O uso da substância composta por poliamida e soro fisiológico, comercializada como um gel aquoso é indicado para diminuir pequenas rugas do rosto, celulites e cicatrizes, além de redesenhar partes assimétricas do corpo, como o bumbum. No entanto, a recomendação médica é que ela seja usada em poucas quantidades, por isso não seria indicado para preencher as nádegas com a intenção de aumentá-las (UOL TV E FAMOSOS, 2014).

Temos aqui, a articulação da busca por fama com certa dose de negligência no uso de tais tecnologias.

Outro ponto de controvérsia reside na discussão acerca do enfoque da grande mídia na veiculação dessa notícia. 0 site UOL argumenta que tal enfoque, de um modo geral, não teve a finalidade de alertar a população. Traduz que o intuito esteve constantemente voltado a criar polêmica com a notícia, objetivando vendagem de revistas, aumento no acesso aos sites relacionados à matéria, jornais, etc. Porém, ao abordar a Rede Globo, sinaliza que ela assumiu um papel de fomentadora do debate acerca da questão do uso do hidrogel como algo nocivo e prejudicial. "Durante os quase 60 segundos de notícia, a emissora entrevistou um médico falando sobre os riscos do hidrogel e também citou que ela ficou conhecida após ficar em segundo lugar no concurso Miss Bumbum" (UOL TV E FAMOSOS, 2014).

Por outro lado, a matéria argumenta que, em outro momento, a mesma emissora divulgava apenas a modelo no período do carnaval, explorando a aparência de um corpo belo e torneado, com aspectos superficialmente saudáveis: "Ela, que aparece na emissora somente durante o Carnaval, ganhou uma matéria falando sobre a situação que se encontra, um quadro grave de infecção" (UOL,2014).

A modelo parece ter se articulado com uma imagem atrelada ao ridículo, estigmatizada como um exemplo negativo dos malefícios que os exageros e a busca pela perfeição de um corpo saudável podem trazer.

\footnotetext{
Marisete de Faveri, mãe da vice-Miss Bumbum, pediu respeito à imagem de sua filha em uma mensagem publicada no fim da tarde desta terça no Facebook. (...) As críticas foram feitas após a divulgação de informações não confirmadas sobre o estado de saúde da apresentadora durante o programa "Cidade Alerta", da Record. No programa de Marcelo Rezende, foi dito que uma auxiliar de enfermagem garantiu que Andressa teria tido uma perna amputada em cirurgia nesta terça (UOL, 2014).
}

O universo digital também é um significativo foco de controvérsias acerca da saúde do corpo na atualidade. Em matéria do site G1, intitulada "Como usar o videogame a serviço do seu corpo", encontramos uma abordagem acerca de como os videogames poderiam auxiliar na saúde com seus sensores de movimento.

Com sensores de movimento e jogos de dança, os videogames mais recentes também servem para sua iniciação no mundo dos exercícios. Eles não substituem um exercício pesado nem são as chaves para uma vida saudável, mas conseguem queimar energia da mesma forma que exercícios leves e podem ser considerados o primeiro passo para espantar o sedentarismo $(\mathrm{G} 1,2014)$. 
Temos aqui a tradução do uso da tecnologia dos videogames como estimulante no condicionamento físico, associados a jogos em que o sujeito pule, dance, gire, etc. Esse argumento defende o videogame como aliado na inserção do indivíduo à prática do exercício físico regular.

Mas a relação de compromisso com o jogo também pode ser trazida para o mundo real na busca por um corpo mais saudável. A dança é uma atividade perfeita para quem quer perder peso, manter os ossos fortes, melhorar a postura e o equilíbrio. E dá para fazer isso jogando! $(G 1,2014)$.

A saúde do corpo acaba por transitar pela diversão, por relacionamentos com outras pessoas, autoestima e criatividade. Temos aqui uma espécie de argumento, visando unir o útil ao agradável.

Outra grande vantagem é que enquanto a criança, o adolescente ou até mesmo o adulto se divertem com a música e tem contato com outras pessoas, elas passam a se sentir muito melhor com seu corpo, abrindo espaço para o desenvolvimento da criatividade e da melhoria da autoestima $(G 1,2014)$.

No trecho a seguir, temos os videogames como aliados da perda de peso e de hábitos saudáveis: "No caso de crianças com sobrepeso, pode potencialmente ajudar a perder peso e a melhorar seus hábitos alimentares" (G1, 2014).

Articulada igualmente ao mundo digital, em matérias veiculadas nos sites Techtudo e Olhar Digital, intituladas "Google quer catalogar material genético para criar 'ser humano perfeito" e "Google quer criar o mapa genético do humano com saúde perfeita" respectivamente, encontramos argumentos acerca da pretensão do grupo Google de cadastrar material genético e trabalhar prevenção de saúde.

O próximo grande projeto do Google tem a ver com genética. O laboratório Google $X$, que realiza as pesquisas mais ambiciosas e arriscadas da empresa, como o Google Glass, o carro autônomo e os balões de internet, agora inicia o "Baseline Study", uma aposta que tem como objetivo criar o mapa genético de um ser humano perfeitamente saudável (UOL OLHAR DIGITAL, 2014).

Estes artigos abordam o Google X, um banco de dados que teria o objetivo de criar um padrão de saúde do ser humano. As propostas da Google voltadas para a área da saúde acabam por trazer nova turbulência acerca do corpo perfeito e saudável.

Esse não é o primeiro nem único projeto do Google no campo da saúde. Em setembro de 2013 a desenvolvedora anunciou a Calico, subdivisão independente que tem como objetivo estender a vida humana. Ejá no mês passado foi apresentado oficialmente o Google Fit, dispositivo que reunirá informações sobre a saúde dos usuários (FREIRE, 2014).

A empresa Google, conhecida por sua inovação tecnológica no ramo da internet, ao buscar potencializar a saúde do corpo, faz tal concepção de saúde circular para algo além do espaço físico. A possibilidade de prolongamento da vida, eliminando doenças e purificando esse corpo de suas imperfeições genéticas, ao criar dispositivos que mapeiem os indivíduos por meio de informações sobre a saúde dos usuários desse mecanismo, está associado à ideia do controle do corpo por parte dos usuários.

O Google também diz que os dados da pesquisa serão anônimos e limitados aos propósitos de pesquisa e para fins médicos, e não serão oferecidos a empresas de seguros, nem serão usados de qualquer outra forma comercial. $O$ uso destas informações também será controlado por quadros institucionais (UOL OLHAR DIGITAL, 2014).

Muito da controvérsia desse projeto está na maneira como essas informações serão manuseadas e armazenadas. 0 objetivo parece estar na prevenção de doenças realizada por meio de um mapeamento do genoma. Argumenta-se pela eficácia no tratamento de enfermidades e no diagnóstico, identificação de anomalias, antes mesmo que a doença evolua no organismo do indivíduo. Apesar dos artigos enfatizarem que esse projeto será utilizado apenas no campo da saúde, uma questão que polemiza a viabilidade desse estudo está relacionada aos critérios que asseguram a proteção e sigilo das informações. Tal projeto poderia inaugurar um mercado futuro para a exploração da indústria de tecnologia e saúde que é reforçada por uma suposta arquitetura corporal ideal. 
Em uma leitura foucaultiana (2004, p. 126), esse entendimento de corpo associado a formas de exploração seria intensificado com o "início das sociedades industriais, [quando] instaurou-se um aparelho punitivo, um dispositivo de seleção entre os normais e os anormais. [...] É dócil um corpo que pode ser submetido, que pode ser utilizado, que pode ser transformado e aperfeiçoado". Assim, temos a produção do corpo ideal se traduzindo como uma condição socialmente imposta que, inclusive, passa a contribuir para suprimir a capacidade crítica em detrimento de padrões estéticos classificatórios. Segundo um grupo de pesquisadores liderados por Maria Elisa Caputo Ferreira, da Universidade Federal de Juiz de Fora, que teceram reflexões sobre a busca do corpo ideal, esse quadro é mais avivado a partir da adolescência. Tal fase da vida é então imbricada ao desejo de corpos esculpidos, magros. Os jovens passam a ser traduzidos como objetos de consumo, refletindo um desejo social de eternização da juventude, conseguido de forma rápida, eficaz e a qualquer preço.

\begin{abstract}
Se fizermos uma observação atenta, notaremos que a mídia possui diversas formas de manipular o corpo e torná-lo objeto de consumo. Nota-se em sua programação receitas fáceis e imediatas para o alcance do corpo socialmente idealizado. Dicas de como se alimentar melhor, usar corretamente os cosméticos, de praticar atividade física para se obter a maior queima calórica, [...] propagação de cirurgias plásticas, lipoaspiração, dietas, exercícios físicos, usos de próteses, remédios e anabolizantes, sendo estes apenas alguns desses recursos científicos oferecidos nos dias atuais (GOMES et al., 2012, p. 200).
\end{abstract}

Essa perseguição ao corpo desejado, controvertidamente, nem sempre caminha lado a lado com a saúde do corpo. 0 corpo socialmente idealizado passa a ser objeto de atenção e estudos, ao mesmo tempo em que vai se colocando como objeto de consumo, incitando investimentos altíssimos. As autoras ainda argumentam que a tecnologia, quando associada aos aparelhos midiáticos como a televisão, a internet, dentre outras, transmitem valores que influenciam na busca por artefatos que promovam a alteração da arquitetura corporal.

\begin{abstract}
Podemos ressaltar este elemento como uma das fontes de transmissão de símbolos que são entranhados nos sentidos do mundo atual e uma das responsáveis pela difusão das técnicas de modificações corporais na busca do belo (ANZAI, 2000). A capacidade de influenciar a sociedade contemporânea e arraigar informações e valores no cotidiano das pessoas é resultado da normalidade que estes meios entram em nossa vida, constituindo um elemento pertencente ao nosso dia a dia (GOMES et al., 2012, p. 200).
\end{abstract}

Sob essa ótica, produz-se a imagem de que um indivíduo culpabilizado por ser "feio" ou sem saúde, conceitos instituídos e estabelecidos em contraposição ao padrão de belo e saudável definidos socialmente. Não possuir o corpo saudável e belo levaria até mesmo a transgredir a fronteira fisiológica do indivíduo (GOMES et al., 2012) e, quando não alcançado esse ideal, essa atitude passaria a ser entendida como atitude de autonegligenciamento. Assim, produz-se a figura de um humano sob o peso da responsabilidade própria, na qual o sentimento de incapacidade poderia desencadear até mesmo patologias e alterações comportamentais - como depressão, anorexia, bulimia, etc.

Nesse sentido, as pessoas que não viessem a atender padrões estéticos relacionados ao peso, à juventude, ao belo e ao saudável estariam se conduzindo pelo propósito de não serem excluídas, marginalizadas e, até mesmo, ridicularizadas, buscando ultrapassar os próprios limites corporais ao recorrerem a intervenções associadas a recursos tecnológicos que transformam e modificam, em sintonia com poderes dominantes.

\footnotetext{
Em plena cultura do individualismo, da independência pessoal e da liberdade (como valores dominantes), vive-se uma espécie de mais-alienação, de rendição absoluta ao brilho não exatamente dos objetos, mas da imagem dos objetos. Mais ainda: rendição ao brilho da imagem de algumas personagens públicas identificadas ao gozo que os objetos deveriam proporcionar (BUCCl; KEHL, 2004, p. 65).
}

Destacamos, ainda, que os autores supracitados tecem considerações em relação à padronização do corpo, questionando 
que corpo você está usando ultimamente? Que corpo está representando você no mercado de trocas imaginárias? E onde a imagem representa o sucesso ou insucesso do sujeito na sociedade? Que imagem você tem oferecido ao olhar alheio para garantir seu lugar no palco das visibilidades em que se transformou o espaço público no Brasil? (BUCCI; KEHL, 2004, p. 174).

Desse modo, corpo e saúde, bem como a articulação dos mesmos, parecem estar sendo produzidos por múltiplos e mediadores na atualidade. Temos aqui uma rede bastante instável e controvertida a misturar corpos, capital, saberes, especialistas, o cidadão comum, a mídia, empresas, medicamentos, etc.

\section{CONSIDERAÇÕES FINAIS}

Diante do presente relato cartográfico, desenvolvido a partir de algumas controvérsias acerca do corpo e da saúde, podemos observar como isso vêm circulando por meio de diversas mediações a envolver acadêmicos, tecnologias, empresas, grande mídia, academias, dentre outros.

Pode-se perceber o quanto tal circuito atual passa por controvérsias que articulam fortemente os exercícios físicos, o uso de cosméticos, as cirurgias estéticas e dietas com as fronteiras de um corpo almejado, desprovido de imperfeições acerca da saúde e da estética. Porém, por outro lado, temos argumentos que apontam para transtornos alimentares como derivados de tal busca do corpo perfeito.

O uso de anabolizantes entra nessa mesma sintonia, na medida em que são igualmente articulados à busca de tal perfeição. A endocrinologia é trazida, nesse momento, a fazer circular tal uso como estando em oposição à saúde das pessoas.

A psicologia também é um importante mediador a colocar a saúde do corpo em circulação, quando traduz uma atualidade focada na imagem, selecionando humanos por sua aparência - e imbricando, portanto, tal imagem com o caráter. Temos aqui, também, a mídia e as celebridades como importantes mediadores (n) dessa imbricação.

Além de aspectos como dietas e exercícios, a genética também é trazida a argumentar pela saúde e estética do corpo. Encontramos traduções que buscam articular os testes genéticos com esses aspectos. Tal promessa, porém, parece ainda ser alvo de instabilidade significativa - foco na eficácia ou não deles diante do emagrecimento.

0 universo digital também é um ponto importante em nosso relato descritivo. Encontramos argumentos que traduzem os videogames como possíveis aliados na luta contra o sedentarismo delineado como nocivo para a saúde - bem como matérias que abordam o projeto Google X. Com tal projeto, a Google lança a promessa de um mapeamento genético voltado para uma saúde preventiva e um forte controle dos corpos. Tal mediação é alvo de fortes contra-argumentos.

Enfim, pudemos percorrer um circuito bastante sinuoso que parece por em evidência um coletivo ainda bastante instável, uma rede que parece argumentar pelo caráter de caixa-cinza das fronteiras daquilo que entendemos por um corpo saudável. 


\section{REFERÊNCIAS}

BACKES, M.T.S. et al. Conceitos de saúde e doença ao longo da história sob o olhar epidemiológico e antropológico. Rev. enferm. UERJ, Rio de Janeiro, 2009 jan/mar; 17(1):111-117.

BOTELHO, Y. Em busca do corpo perfeito. Revista Veja Rio. 2014. Disponível em: <http://vejario.abril. com.br/materia/cidade/teste-mapeamento-dna-fitness/> Acesso em: 18 out. 2015.

BRASIL. Ministério da Educação. Saúde. 1997. Disponível em: <http://portal.mec.gov.br/seb/arquivos/ pdf/livro092.pdf> Acesso em: 19 out. 2015.

BRANDL NETO, I. ; CAMPOS, I. G. de . A influência da mídia sobre o ser humano na relação com o corpo e a autoimagem deadolescentes. Caderno deEducação Física. Marechal Cândido Rondon, v. 9, n. 17, p. 87-99, 2. sem., 2010. Disponível em: $<$ https://www.google.com.br/url?sa=t\&rct=j\&q=\&esrc=s\&source=web\&cd=2\&ved=0 ahUKEwjUq4mr2uLJAhVJgpAKHQJ3AUoQFgglMAE\&url=http\%3A\%2F\%2Fe-revista.unioeste.br\%2Findex. php\%2Fcadernoedfisica\%2Farticle\%2Fdownload\%2F4531\%2F3854\&usg=AFQjCNGE3e7MFH9st9F_ zym662wPkK6iBA\&cad=rja>. Acesso em: 17 out. 2015.

BUCCl, Eugênio; KEHL, Maria Rita. Videologias: ensaios sobre televisão. São Paulo: Boitempo, 2004. (Estado de Sítio). Disponível em: <https://books.google.com.br/ books?id=TvHblq0OMX8C\&pg=PA65\&lpg=PA65\&dq=\#v=onepage\&q\&f=false $>$ Acesso em: 17 out. 2015.

COELHO, Maria Thereza Ávila Dantas; ALMEIDA FILHO, Naomar de. Conceitos de saúde em discursos contemporâneos de referência científica. Hist. cienc. Saúde - Manguinhos, Rio de Janeiro, v. 9, n. 2, p. 315-333, Aug. 2002. Available from $<$ http://www.scielo.br/scielo.php?script=sci_arttext\&pid=S010459702002000200005\&lng=en\&nrm=iso $>$. Acesso em: 19 out. 2015.

CORPORE. 0 corpo perfeito saudável e sem anabolizantes. 2014. Disponível em: $<$ http://revistacorpore. com.br/novo_portal/?portal=doloribus-tenetur-eum-blan> Acesso em: 19 out. 2015.

FONSECA, Angélica Ferreira (Org.). 0 território e o processo saúde-doença. Rio de Janeiro: EPSJV/Fiocruz, 2007.

FOUCAULT, M. Os corpos dóceis. Vigiar e punir: nascimento da prisão. 29. ed. Tradução de Raquel Ramalhete. Petrópolis, RJ: Vozes, 2004, p. 125-52.

FREIRE, R. Google quer catalogar material genético para criar 'ser humano perfeito' TechTudo. 2014. Disponível em: <http://www.techtudo.com.br/noticias/noticia/2014/07/google-quer-catalogar-materialgenetico-para-criar-ser-humano-perfeito.html>. Acesso em: 18 out. 2015.

G1. Como usar o videogame a serviço do seu corpo. 2014. Disponível em: <http://g1.globo.com/cienciae-saude/especial-publicitario-ministerio-da-saude/saude-na-escola/platb/2014/06/26/como-usaro-videogame-a-servico-do-seu-corpo/>. Acesso em: 19 out. 2015.

GOMES, L. F. ; COELHO, F.D. ; GOMES, D. F. ; ANDRADE, M.R.M ; FERREIRA, M. E. C. ; MAIA, R. R. . A busca do corpo ideal: refletindo sobre a influência da mídia na satisfação corporal de mulheres e o papel do educador físico nesse sentido. In: IV Encontro Nacional da Midia Esportiva, 2012, São João Del Rei. Anais do IV ENOME. São João Del Rei: Labomídia, 2012. v. 4. p. 199-203. Disponívelem:_https://www.google.com.br/ url?sa=t\&rct=j\&q=\&esrc=s\&source=web\&cd=28ved=0ahUKEwiY2oggzOLJAhVLfpAKHRKXDOsOFggiMAE\&url=http\%3A\%2F\%2Fwnw. labomidia.ufsc.br\%2Findex.php\%2Fenome\%2Fiv-enome-2012\%2Fanais-iv-enome\%2Fdoc_download\%2F499-28-a-busca-do- 
corpo-ideal-refletindo-sobre-a-influencia-da-midia-na-satisfacao-corporal-de-mulheres-e-o-papel-do-educador-fisico-nesse-se ntido\&usg=AFOjCNFqGKZCGMrVJjM2E4kVRNqM94Cvmw\&cad=rja >. Acesso em: 17 out. 2015.

LATOUR, B. Ciência em ação: como seguir cientistas e engenheiros sociedade afora. São Paulo: Editora UNESP, 2000.

Reensamblar Lo Social: uma introdución a la teoria del actor-red. Buenos Aires: Manantial, 2008.

LUNARDI, V.L. Problematizando conceitos de saúde a partir do tema governabilidade dos sujeitos. Revista Gaúcha Enferm., Porto Alegre, v.20, n.1, p.26-40, jan. 1999.

RIOS, Ediara Rabello Girão et al. Senso comum, ciência e filosofia: elo dos saberes necessários à promoção da saúde. Ciênc. saúde coletiva [online]. 2007, vol.12, n.2, pp. 501-509. ISSN 1413-8123.

ROSA, Yasmin. A ditadura da estética: a busca pelo corpo perfeito. Revista PUC-RIO Digital. 2009. Disponível em: <http://puc-riodigital.com.puc-rio.br/Texto/Ciencia-e-Tecnologia/Ditadura-daestetica\%3A-a-busca-pelo-corpo-perfeito-4306.html\#.VVOVg45VhHw>. Acesso em: 18 out. 2015.

SABROZA, P.C. Condições de vida, doença, e saúde no Brasil na conjuntura atual, o processo de saúde e doença. Módulo 2. Rio de Janeiro: Fiocruz, 2001.

SAFATLE, Vladimir. O que é uma normatividade vital? Saúde e doença a partir de Georges Canguilhem. Sci. stud., São Paulo, v. 9, n. 1, p. 11-27, 2011 . Available from <http://www.scielo.br/scielo. php?script=sci_arttext\&pid=S1678-31662011000100002\&lng=en\&nrm=iso >. Acesso em: 18 dez. 2015.

SANTOS, L. G. Politizar as novas tecnologias (impacto sociotécnico da informação). São Paulo: Editora 34, 2003.

SBISSA, Pedro Paulo Mendes ; SCHNEIDER, Daniela Ribeiro; SBISSA, Antônio Silveira . Caracterização do desenvolvimento epistemológico da saúde e das práticas complementares. ACM arq. catarin. med; 40(2)abr.-jun. 2011.

SIBILIA, Paula. O homem pós-orgânico: corpo, subjetividade e tecnologias digitais. Rio de Janeiro: Relume Dumará, 2002.

Rumo à imortalidade e à virtualidade: a construção científico-tecnológica do homem pós-orgânico. 2001. Disponível em <http://www.intercom.org.br/papers/nacionais/2001/papers/NP8SIBILIA.PDF>. Acesso em: 05 maio 2015.

UOL OLHAR DIGITAL. Google quer criar o mapa genético do humano com saúde perfeita. 2014. Disponível em: <http://olhardigital.uol.com.br/noticia/google-quer-criar-o-mapa-genetico-do-humano-comsaude-perfeita/43262>. Acesso em: 19 out. 2015.

UOL TV E FAMOSOS. Andressa Urach já respira sem a ajuda de aparelhos, diz boletim médico. 2014. Disponível em: <http://celebridades.uol.com.br/noticias/redacao/2014/12/03/andressa-urach-jarespira-sem-a-ajuda-de-aparelhos-diz-boletim-medico.htm>. Acesso em: 19 out.2015.

UOL TV E FAMOSOS. Globo destaca estado de saúde de Andressa Urach em telejornal. 2014. Disponível em: <http://televisao.uol.com.br/noticias/redacao/2014/12/03/globo-destaca-estado-de-saude-deandressa-urach-em-telejornal.htm>. Acesso em: 19 out. 2015. 